\title{
Development of preschool teachers' gaming competence
}

\author{
T.G. Khanova ${ }^{1 *}$, N.V. Belinova ${ }^{2}$, and N.V. Vyalova ${ }^{3}$ \\ ${ }^{1}$ Minin Nizhny Novgorod State Pedagogical University, Nizhny Novgorod, Russia \\ ${ }^{2}$ Minin Nizhny Novgorod State Pedagogical University, Nizhny Novgorod, Russia \\ ${ }^{3}$ Minin Nizhny Novgorod State Pedagogical University, Nizhny Novgorod, Russia
}

\begin{abstract}
The creative game has its history, but it remains one of the urgent problems of modern pedagogy. Being the leading activity, containing the prerequisites for the formation of the most important psychological growths, the game is lagging, giving priority to educational activities. According to the authors, there is no unified approach to understanding the essence of the game, its motives, miscomprehension of its importance and enormous developmental potential, the attitude of adults to game as an unnecessary activity. The authors see the solution to this problem in the development of teachers' professional competence in pedagogical support of children's game, or gaming competence. The teacher, as a key subject of the educational process, needs to have a system of professional knowledge, game experience, personal qualities to make optimal conditions for the children's game development, as well as the strive for self-development and creative growth. The article presents a project of methodological support for teachers, including four thematic modules, and implemented based on modern educational technologies. The probe results of this project drove to the conclusion about the effectiveness of improving the gaming competence of teachers by competently building the content and technologies of methodological work in a kindergarten.
\end{abstract}

\section{A problem statement}

Modern preschoolers live in the predominance of passive leisure and the gradual destruction of the children's game subculture. This is largely due to the rapid development and availability of the Internet, even for younger preschoolers. Parents often do not have enough time, desire, and will to fill children's leisure time and play with the child, therefore, various kinds of gadgets begin to take an increasing place in their life. Many children are already losing interest in traditional games and toys, becoming more and more carried away by the world of computer games and watching cartoons. In such a situation, parents delegate responsibility for the content and organization of children's games to preschool teachers.

On their accord, pre-school teachers have insufficient gaming competence because the

\footnotetext{
* Corresponding author: prof-ped.gpa@mail.ru
} 
programs of pedagogical universities pay little attention to the organization of children's games and the design of game technologies. The gaming competence of a teacher is integrative professional and personal quality, reflecting the level of knowledge, abilities, skills, and experience of the teacher for managing children's games.

Many preschool teachers strive to take control of children's games: children play games chosen for them by educators, get ready-made roles without the right to choose. Thus, they play according to a predetermined algorithm, a plan. When the teacher intervenes in the game, children's ideas are transformed or collapsed, the children are not interested in the game. In the programs of preschool educational institutions, especially for older groups, a large number of classes are laid down, and about one hour is allotted for independent games for children. As a result, preschoolers lose the skill of communicating with each other, often do not know how to show empathy and support.

Besides, the problem of the development of teachers' gaming competence in preschool educational institutions in the scientific and methodological literature is considered fragmentarily: there are no complex works devoted to this topic. Researchers pay attention to the structure of gaming competence, the conditions and methods of its development (works by T.V. Evdokimova, R.I. Zhukovskaya, E.V. Zvorygina, N.G. Zdorikova, A.V. Kalinchenko, I.L. Kirillova, I.A. Komarova, E.E. Kravtsova, O.V. Leshchinskaya-Gurova, L.L. Lopatina, I.P. Lotova, D.V. Medzheritskaya, Yu.V. Miklyaeva, S.L. Novoselova, N.N. Poddyakova, E.I. Rzayeva, V.N. Sidorenko, E.O. Smirnova, E.B. Tesley, E.V. Trifonova, G.V. Yakovleva and others).

Some works are devoted to the study of teacher competencies in general (studies by V.V. Abalina, V.I. Baydenko, T.P. Zarutskaya, E.F. Zeer, V.B. Kashkareva, V.A. Fomicheva, and others).

The range of scientific and methodological literature on the topic under consideration is rather limited, which also confirms the relevance of the study.

\subsection{The objective of the work}

The objective of the study is to theoretically substantiate and experimentally prove the effectiveness of pedagogical conditions, means, and methods of developing the gaming competence of preschool teachers.

This objective involves solving the following tasks:

1. To consider the content of the concept of "gaming competence of teachers" in modern research, analyze the structure and features of gaming competence of preschool teachers.

2. To highlight the objectives of methodological work on the development of preschool teachers' gaming competence.

3. To consider the forms and means of methodological work on the development of preschool teachers' gaming competence.

4. To survey the level of gaming competence of preschool teachers.

5. To develop a system of methodological work on the development of preschool teachers' gaming competence.

6. To analyze the results of experimental research work on the development of preschool teachers' game competence.

\section{Results of the research}

Studies show that modern preschoolers play less often than other generations and not so well. If back in the middle of the twentieth century, the game was considered as the norm [1], now only $6 \%$ of older preschoolers are involved in it. Most children perform typical, 
monotonous manipulations with toys and are not able to independently come up with the plot of the game, interact with peers [2].

A role-playing game in children will develop only in adults' systematic work in this direction. A child's ability to play is formed when one masters the ways of playing from someone who already owns play forms. Previously, older children acted as such "teachers" of the game, but in the modern world, this function should be taken on by adults, mainly preschool teachers. However, it is adults who often do not want to play with children, do not pay due attention to this. E. Singer emphasizes that the specifics of play activity require the teacher to be aware of the fact that full-fledged play contributes to the growth of adaptation to the environment, the child's self-confidence, and therefore, successful socialization, that is why it is necessary to "carefully" treat this type of activity, accompanying songs, dances, humor.

As noted by E.I. Rzayev, often educators simply do not know how to play and do not fully understand how important a game is in the educational process [3]. At the same time, the preschool education standard puts forward clear requirements for teachers regarding the organization of play activities in kindergarten. Thus, the success of the organization of preschoolers' play activities directly depends on the teacher's professional gaming competence, on how one manages the game activities of preschoolers.

Also, preschool teachers, providing the conditions for the children's game and playing, often do not take into account the peculiarities of the modern children's subculture and limit them to an artificial subject-play environment. Teachers do not distinguish between free play and activities, as a result of which game as an independent form of children's life is gradually disappearing [4].

Many researchers consider the activity component to be an important characteristic of the play position, that is, the teacher's play experience - a complex of the teacher's practical skills to use the elements of the role-playing game (role, plot, content, etc.), to direct the child's game.

The problem of developing the gaming competence of preschool teachers remains one of the most acute. There are several reasons for this.

First, throughout the development of preschool education, different and often contradictory technologies for the development and upbringing of preschoolers and, as a consequence, the professional competence of teachers prevailed.

Secondly, the overwhelming majority of teachers believe that the development of preschoolers should be carried out according to already-debugged educational schemes and technologies.

Thirdly, those ways of mastering the qualifications of preschool teachers that are currently used are often multidirectional and do not always meet the actual needs of educators. Professional development, among other things, is carried out from time to time, unsystematically.

E.I. Rzayeva identified 6 indicators of gaming competence of preschool teachers [3]:

1. Valuable attitude of the teacher to the game. The preschool teacher must know the goals and objectives of psychological and pedagogical support of game activities, understand the importance of role games for the development and upbringing of preschool children, how to organize it to support the mental development of children.

2. Generalized game theory. A preschool teacher must know the theoretical basis of game activity, have a personal view of the theoretical basis of the game.

3. The level of development of the game space. A preschool teacher must be able to transform real objects into playable ones, be able to integrate individual game spaces, and in real situations to involve several game meanings.

4. The teacher's readiness to play. A preschool teacher must know the techniques, methods, and ways of implementing psychological and pedagogical support for the game 
activity of preschool children, freely move from knowledge of how to control the game to specific actions.

5. The complect of personal qualities. A preschool teacher must show play initiative, be creative, show empathy, be creative in solving game problems, understand the play states of children, and be able to carry out self-analysis.

6. Gaming experience. A preschool teacher must support and transform disordered children's games in a pre-planned direction of the storyline, have a game experience, that is, develop storylines, enrich the content of children's games through personal role-playing behavior.

According to E.I. Rzayeva, gaming competence is determined by a set of structural components: psychological and pedagogical knowledge, play skills, and the teacher's attitude to the game [3].

I.A. Komarova, A.A. Kuleshova, N.G. Zdorikova believe that the professional-gaming competence of a teacher is made up of special personality and character traits, namely: the teacher's humanistic position to children, the experience of his playing culture, intelligence, the ability and willingness of educators to use game technologies in work with children [6].

According to E.O. Smirnova, the teacher's gaming competence presupposes, first of all, the ability to play, since only a teacher knows how to do it and who loves to play will be able to transfer game knowledge and skills to children [5]. The teacher must be able to come up with game situations and plots, highlight something extraordinary, unusual in familiar objects and toys, be able to put away standards and stereotypes. This means that the teacher must have a developed imagination, which allows stimulating preschoolers to independently create imaginary situations [7].

E.O. Smirnova said that a teacher must love and play: have a rich imagination, take on any roles, express oneself emotionally and transfer this state to children [8].

ON. Korotkova believes that the main task of the teacher is to determine the zone of proximal development of the game, and not just joint playing with children. In other words, the teacher should be ahead of the playing potential of children, involve them in a game of a higher order and show them new opportunities [9]. So, at the age of 2-3 years, the child, together with the teacher, learns to use objects and toys in a new capacity, that is, to create game substitutions. A child 3-4 years old can take a play role, come up with imaginary situations. Children over 5 years old can play fantasy games, combine events and build complex game plots. Accordingly, the teacher should be able to do all this with higher quality and purposefulness than children, to come up with new events and statements, game images, and situations.

The gaming competence of a teacher is not only the ability to come up with new plots and games. First of all, a game is an action, so children should be involved in the game, help them enter an imaginary situation, take on the role of another, and take the place of the character. The teacher must be able to convey his interest in the game to children emotionally, artistically, and convincingly, with special expressive gestures, intonation, and facial expressions.

However, in this case, the teacher's emotionality and artistry can supplant the children's playing initiative. Of course, children are not as expressive and emotional as teachers, it is more convenient and easier for them to watch from the outside how the teacher "acts" than to take the initiative themselves. Consequently, the teacher must sometimes step into the background, "giving way" to the child, but at the same time directing the children's playing activity and initiative, supporting them in their endeavors, in other words, to be able to hear children. This is often difficult if the teacher does not clearly understand exactly how to play, and the children are not yet capable of this.

Thus, the requirements for the teacher's gaming competence can be reduced to the following aspects: 
- developed imagination, creativity, freedom of design and action;

- emotional expressiveness, artistry;

- tact, sensitivity to a partner, communication skills.

These qualities are not only manifested, but also formed in the game.

In his other work, E.O. Smirnova notes that, first of all, the structure of the teacher's gaming competence includes creativity and a developed imagination [8]. The teacher should be able to come up with new, unusual games, change the plots of familiar games, play up typical situations, not be afraid to experiment. Such qualities as sensitivity and tact are no less important for a teacher. The teacher cannot control the game from above, telling children what to do and controlling them. The teacher should be a direct participant in the game, monitor his activity in the game, but at the same time maintain the plan and game intent of the game, playing along with the children in time or stepping aside when needed. The teacher should be aware of folk, national, courtyard, and modern games, which are a special component of the children's subculture of the past and present and have great pedagogical capabilities [10].

Thus, the teacher's gaming competence is based on many components of his professional training. It is formed not in theory, but practice, through the use of active teaching methods.

According to E.B. Tesley, several psychological and pedagogical conditions contribute to an increase in the gaming competence of teachers, among them: the level of the material and technical base; the readiness of the subjects of the educational process for common activities; communication between teachers and pupils; creating conditions for establishing feedback through this communication [11].

The development of gaming competence of preschool teachers occurs both directly in practice, in the process of work, and special classes in kindergarten. However, as noted above, preschool teachers do not pay enough attention to the organization of the game, so it develops spontaneously, or they control it too much and interfere too much in it. Insufficiently formed gaming competence of teachers is often the reason for the deficit of children's playing activity; strict regulation of the game, the imposition of stereotyped plots and roles, total interference in the game leads to its disintegration [12].

Difficulties in the development of gaming competence of preschool teachers are largely related to the peculiarities of the game, its essence. Game is an independent activity of children, however, teachers strive to control it and direct it in the way they need, since many of the educators repel, according to E.V. Trifonova, from the "adult-centered" model of play, according to which children become objects, not subjects of the game [13]. With the direct guidance of children's games, preschool teachers train specific game actions, draw attention to the external signs of game inherent in a particular role, to specific procedures, etc., and not to the essence of the role and game. All this does not allow children's games to develop, and the skills of the professional activity of teachers also do not develop.

How can the development of games be promoted, without hindering the independence, initiative, and creativity of children? In the work of A.V. Kalichenko, Yu.E. Miklyaeva, and V.N. Sidorenko, dedicated to the pedagogical technologies of guiding the preschooler's game in kindergarten, it is noted that in the joint game in preschool education the teacher should be a playing partner for children and at the same time bearer of a special "language" of game. If the teacher behaves openly, emotionally, and naturally, agrees to accept the conditions of children's games, does not limit the freedom of action of children, this will contribute to the fact that children will enjoy the game, will independently master the game methods. Besides, the game should remain a free independent child's activity: children should be able to freely use any toys, communicate with each other and come up with game situations [14]. The authors show how the position of the educator in the game is 
transformed as the child's activity changes. At the first stage, the teacher is the main "hero" of the game and directly tells the children what to do, or asks questions, guiding the game. Then the teacher becomes one of the secondary characters in the game [14].

Some foreign scientists note that many teachers need training in mastering adequate methods of guiding children's group games:

1) playful involvement of teachers, emotional closeness;

2) play the interaction of an adult with children;

3) unobtrusive participation in the game [15].

According to many researchers (E.O. Smirnova, L.P. Strelkova, G.G. Kravtsov, E.L. Berezhkovskaya, and others), the development of a child's personality is impossible without the necessary development of the personality of the teachers, since "personality can develop a personality". Consequently, to make the necessary conditions for the development of children's games, it is necessary to provide personality-oriented training for the teachers, as a result of which their professional-play competence will be developed. The implementation of this type of teacher training is possible subject to several principles and conditions. It should be noted that a person will act personally only if one feels to be the source of their behavior and activity, as L.S. Vygotsky stated [16]. Consequently, even with personality-oriented learning, the teacher must become and feel himself to be its source, therefore the teacher's ability to self-development and self-education, the ability not only to orient but also to actively participate in innovative processes is recognized as one of the leading factors in increasing professional competence [17, 18]. According to N.V. Belinova, T.G. Khanova, a well-thought-out organization of methodological work will contribute to the development of a high level of professional-game competence of teachers, ensuring the development of personal qualities that are significant for successful professional activity [19].

The study is based on the use of a complex of research methods: system analysis, classification, comparison, questionnaires, pedagogical experiment, observation, conversation.

The study was made based on preschool institutions in the city of Nizhny Novgorod. 20 teachers were involved in the probe.

The experimental study was carried out in three stages.

The first stage, the ascertaining experiment, was aimed at determining the level of development of the creativity of preschool teachers.

The second stage is a formative experiment, the goal is to develop and test a system of measures for the development of creativity, including interactive methods.

At the third stage of the control experiment, the following tasks were solved:

1) to measure the level of development of teachers' creativity;

2) compare the obtained results of the ascertaining and control experiments, determine the degree of work efficiency.

At the first stage of the experimental work, the level of gaming competence of preschool teachers was identified.

The measurement of the level of gaming competence of preschool teachers was carried out as a measurement of the quality of the activity, that is, using a questionnaire, interview, and written questioning and the method of unfinished sentences.

The competence of teachers in the field of organizing and developing the game activity of preschoolers was analyzed. The teachers' answers to the first block of questions related to the management of children's game activities showed that most teachers make conditions for the initiation and deployment of children's game and the development of children's communication in-game, encourage children to play, long to maintain a balance between different types of games, try to take into account the personal characteristics and individual needs of children. However, certain problems were identified with the management of 
children's game activities in teachers' actions: non-observance of the balance between game and other types of activity in the pedagogical process, regulation of children's game, reproduction of the same type of plots and play actions by children, insufficient stimulation by the teacher of using substitute objects in-game, interference in the course of children's free game. The teachers' answers to the second block of questions-situations showed that teachers cannot formulate the conditions for children's game: they offered, in general, rather vague solutions: "to interest children", "create conditions for the game", "to play with children" etc. According to teachers, the main thing in the management of role-playing games is the help of the educator (explanation, providing game material) and the creation of game situations. All subjects noted that they had no problems with organizing various types of games. The reason children play little, according to teachers, is that most of the time in kindergarten is spent in classes. Besides, children cannot come up with games on their own, they do not have enough creative ideas. It is noteworthy that not a single teacher indicated his incompetence in gaming (inability to organize and conduct children's games) or unwillingness to play with children as a reason. The teachers' answers to the third block of questions related to their personal qualities made it possible to conclude that teachers try to act according to a predetermined plan, not deviate from standard actions, many of them are afraid to show their creativity and express ideas, fearing that they will be criticized. All these factors negatively affect the development of teachers' gaming competence [20]. It can be assumed that the level of gaming competence of preschool teachers does not fully meet the requirements put forward by the higher education system for this category of specialists.

Based on the results of diagnosing the level of gaming competence of preschool teachers, specific gaps in its development were identified, the correction of which is suggested by the developed system of methodological work:

1. Failure to maintain a balance between game and other activities in the pedagogical process.

2. Regulation of children's game by the teacher and, as a consequence, the reproduction of the same type of plots and game actions by children.

3. Insufficient stimulation by the teacher of the use of substitute objects in the game.

4. Unjustified interference of the teacher in the course of children's free game.

5. Reluctance of teachers to deviate from a well-thought-out plan, standard behavior in repetitive situations, lack of creativity, and riskiness.

The identified problems necessitated the development of a system of methodological work on the development of gaming competence of preschool teachers, which includes 4 thematic modules that differ from each other both in content and in the forms of work with teachers $[21,22]$.

In the theoretical part of the work with teachers, mainly those issues were raised that, as shown by diagnostics, cause difficulties for preschool teachers. Moreover, the teachers received theoretical knowledge not in the form of ready-made lectures, but through practice - in the course of discussions.

The module "Development of the teacher's personal qualities" was aimed mainly at developing the personal component of gaming competence in teachers. Within the framework of this module, teachers composed new children's games, new endings of traditional games and played them with their pupils and themselves, which made it possible to develop imaginative thinking, imagination, and creativity in both teachers and children.

The third module "Immersion in the game" was that teachers learned to be not teachers, but playing partners with whom the children felt free and equal, but at the same time, at each new stage, preschoolers "discovered" and learned more complex ways of building a game thanks to the teacher. The module is aimed at developing an activity component for teachers, that is, the gaming experience. 
The module "Correcting mistakes" assumed the observation of teachers at the work of their colleagues, namely: teachers came to classes in parallel groups and observed from the side how the children's game proceeds, what role the teacher plays in it.

At the final module, an auction of pedagogical ideas was organized, at which preschool teachers exchanged their experience and spoke out their original games, the task for which they received in the second module.

At the control stage of the experimental research work, a repeated diagnostics of the level of development of gaming competence of preschool teachers was carried out. The final stage of the control study was the distribution of teachers according to the levels of development of their gaming competence. Each teacher was assigned to one of three levels of gaming competence development.

Thus, three levels of preschool teachers' gaming competence were identified: low, medium, and high.

The low (intuitive) level of the development of preschool teachers' gaming competence indicates that the teacher does not clearly and unclearly understand the goals and objectives of its development. Gaming competence is not perceived as a criterion for professional activity. The teacher does not show initiative in obtaining additional information on this topic, explaining that such knowledge is not useful in the profession. Such a teacher builds children's games according to generally accepted and well-established patterns, without showing creativity and initiative.

The average (normative) level of development of preschool teachers' gaming competence is characterized by a stable, holistic attitude of teachers to gaming activity. Such a teacher can plan children's games and evaluate their possible results. In familiar situations, the teacher seeks to find new images and solutions, but reproductive forms of thinking prevail.

A high (active) level of development of preschool teachers' gaming competence is characterized by the fact that the teacher longs to constantly acquire new knowledge, improve the gaming activity of children and one's own. The teacher regularly evaluates his work, seeks to understand the motivation of children and their actions. Such a teacher is capable of creative improvisation, effective solutions to game problems.

Thus, we can note the predominance of the normative (average) level of development of preschool teachers' gaming competence. Based on the results of the survey undertaken, as well as the data obtained in the process of questioning and conducting the methodology of unfinished sentences, it was concluded that teachers, in general, understand what the "teacher's game culture" is, but not clearly and enough.

Based on the results of the analysis of the control experiment, we found that most of them, regardless of work experience and age, began to better manage children's game, although some teachers still find it difficult to be in an imaginary situation. However, most of the educators began to play better and better.

Thus, it was revealed that the level of preschool teachers' gaming competence at the control stage of experimental research work sufficiently meets the requirements put forward by the higher education system for this category of specialists.

\section{Conclusions}

The conditions for the development of preschool teachers' gaming competence are: planning by teachers of work on the development of children's game, the development of the personality of the teachers (student-centered learning), the presence of internal motivation of teachers to learn, the desire for self-improvement, developed methodological work in preschool. 
The effectiveness of work on the development of preschool teachers' gaming competence is conditioned, firstly, by taking into account the components included in the structure of the teacher's professional competence, namely: personal, cognitive, and activity components; secondly, the simultaneous work on the development of all the components that make up the structure of the teacher's professional competence, but at the same time, the main attention was paid to the activity component - the teacher's gaming experience.

\section{References}

1. D.B. Elkonin, Psychology of the game (1999)

2. E.O. Smirnova, I.A. Ryabkova, Psychological features of the play activity of modern preschoolers, Questions of psychology, 2, 15-23 (2013)

3. E.I. Rzayeva, Criteria and indicators of the level of development of play competence of future educators of preschool educational institutions, Yaroslavl Pedagogical Bulletin, 3, 170-174 (2016)

4. Elly Singer, Game and playfulness in early childhood education and care, Psychology in Russia: State of the Art, 8(2) (2015)

5. E.O. Smirnova, Educator's gaming competence, Modern preschool education, 9, 4-9 (2017)

6. A.I. Komarova, Research of the phenomenon of professional-game competence of future preschool specialists, Vector of Science, 3 (2010)

7. G.G. Kravtsov, E.E. Kravtsova, Psychology of the game (cultural-historical approach) (2017)

8. E.O. Smirnova, Game in modern preschool education, Psychological science and education, 3, 92-97 (2013)

9. $\quad$ N.A. Korotkova, A story-driven game (2016)

10. N.A. Shamanova, T.G. Khanova, Development of play competence of preschool teachers, Kindergarten from A to Z, 3, 82-92 (2020)

11. L.M. Volobueva, Active teaching methods in the methodological work of a kindergarten, Management of preschool education, 6, 70-78 (2012)

12. N.A. Shamanova, T.G. Khanova, G.S. Gorkova, Study of the level of play competence of teachers of a preschool educational organization, Problems of modern pedagogical education, 68(4), 263-266 (2020)

13. E.V. Trifonova, What is a "good game": the position of the teacher (reflection on one questionnaire), Kindergarten from A to Z, 3(87), 4-22 (2017)

14. A.V. Kalinchenko, Yu.V. Miklyaeva, V.N. Sidorenko, The development of the game activity of preschoolers (2004)

15. E. Singer, M. Nederend, L. Penninx, M. Tajik, \& J.Boom, The teacher's role in supporting young children's level of play engagement, Early Child Development and Care, 184, 1233-1249 (2014)

16. L.S. Vygotsky, Game and its role in the mental development of the child, Journal of the Psychological Society named after L.S. Vygotsky, 1, 2-18 (2000)

17. O.I. Vaganova, I.S. Vinnikova, L.A. Sundeeva, M.M. Kutepov, A.A. Popkova, Development of professional-pedagogical focus of a teacher in vocational training, Amazonia Investiga, 9(25), 350-355 (2020) 
18. I.Y. Burkhanova, G.L. Drandrov, S.S. Ivanova, A.V. Stafeeva, N.B. Vorobyov, V.A. Balchugov, E.V. Ignatyeva, Technological Support of Professional Self-Development of Teachers in the System of Lifelong Learning, International Journal Of Applied Exercise Physiology, 9(4), 117-124 (2020)

19. T.G. Khanova, N.V. Belinova, Continuous education of preschool teachers: methodological support for improving professional competence, Problems of modern pedagogical education, 67(3), 240-243 (2020)

20. I.B. Bicheva, S.N. Kaznacheeva, Development of legal competence of a teacher of preschool education, Vestnik of Minin University, 8(4), 1 (2020)

21. O.A. Kozyreva, Pedagogical modeling in the professional activity of a teacher and a scientific-pedagogical worker, Vestnik of Minin University, 8(2), 1 (2020)

22. L.A. Sundeeva, E.V. Lukina, L.Y. Shobonova, L.I. Kutepova, Z.V. Smirnova, Forms and teaching methods in the system of continuing professional education, Propositos Y Representaciones, 9 (2021) 